\title{
Editorial
}

\section{Natural Fiber Reinforced Polymer Composites}

\author{
Md. Saiful Islam, ${ }^{1}$ Adriana Kovalcik, ${ }^{2}$ Mahbub Hasan, ${ }^{3}$ and Vijay Kumar Thakur ${ }^{4}$ \\ ${ }^{1}$ Department of Chemistry, Faculty of Science, Universiti Putra Malaysia, 43400 Serdang, Selangor, Malaysia \\ ${ }^{2}$ Institute for Chemistry and Technology of Materials, Graz University of Technology, Stremayrgasse 9, 8010 Graz, Austria \\ ${ }^{3}$ Department of Materials and Metallurgical Engineering, Bangladesh University of Engineering and Technology, \\ Dhaka 1000, Bangladesh \\ ${ }^{4}$ School of Mechanical and Materials Engineering, Washington State University, P.O. Box 642920, Pullman, WA 99164-290, USA \\ Correspondence should be addressed to Md. Saiful Islam; msaifuli2003@yahoo.com \\ and Adriana Kovalcik; adriana.gregorova@tugraz.at
}

Received 20 August 2015; Accepted 20 August 2015

Copyright (C) $2015 \mathrm{Md}$. Saiful Islam et al. This is an open access article distributed under the Creative Commons Attribution License, which permits unrestricted use, distribution, and reproduction in any medium, provided the original work is properly cited.

The use of natural fibers as a reinforcement for various materials was recorded already in ancient Egypt; however, their rediscovery can be dated to the beginning of 20 th century. Current special issue is devoted to the role of natural fibers as reinforcements for various biodegradable and nonbiodegradable polymer matrices. The application of natural fillers can be seen as an approach to adjust material performance of polymer composites supposing that filler/matrix interactions will be optimized and a hygroscopicity of natural fillers will be hindered. This special issue contains 16 papers that highlight a number of reasons for applications of natural fillers in polymer composites. In recent years the discussion about a balance in carbon footprint increased an attractiveness of natural fibers/fillers derived from agricultural sources predominantly from one-year plants.

One of the reasons given for using of fibers from oneyear plants can be a quicker and economically favorable production of composites based on environmentally friendly, abundant renewable materials with short growth cycles. A large variety of natural fibers/fillers are available worldwide, although their chemical and physical nonuniformity in comparison with synthetic fibers often requires an inclusion of pretreatment steps as well as a precise characterization before their applications. S. Shahinur et al. in the paper "Characterization on the Properties of Jute Fiber at Different Portions" reported that physicomechanical properties of Jute Fibers vary within one batch, depending on a selected cut position (lower part, middle part, and top of $250 \mathrm{~mm}$ long fibers). Md. M. Rahman et al. in the paper "Synthesis of Cotton from Tossa Jute Fiber and Comparison with Original Cotton" studied properties of synthesized cotton from Tossa Jute Fiber using the processing steps such as extraction in water, disintegration, drying, dewaxing, and delignification. This work shows that chemical structure and thermal stability of cotton from Tossa Jute Fibers are comparable with cotton fibers derived from cotton plant. N. Bidin et al. in the paper "Suitability of Aquatic Plant Fibers for Handmade Papermaking" advised aquatic plants such as Scirpus grossus, Cyperus rotundus, and Typha angustifolia as suitable materials for pulp and paper industry. B. Tisserat et al. in the paper "Ionic Liquid-Facilitated Preparation of Lignocellulosic Composites" introduced EMIMAc (ionic liquid) in the pretreatment step of lignocellulosic material (mixture of cotton and steam exploded wood) and various reinforcement fabrics to enhance the existing properties (especially mechanical) of polymer composites procured from renewable materials.

Another purpose of using natural filler can be a modification of rheological and mechanical properties of polymer composites without an increase of composites weight and costs. Papers within this issue address utilization of natural fibers as reinforcements for thermosets as well as thermoplastics. S. D. Salman et al. in the paper "Physical, Mechanical, and Morphological Properties of Woven Kenaf/Polymer 
Composites Produced Using a Vacuum Infusion Technique" reinforced epoxy resins with plain woven kenaf fabric with fiber content of $35 \mathrm{wt} . \%$ and detected superior mechanical properties of composites cut in $0^{\circ} / 90^{\circ}$ orientation.

V. A. Escócio et al. in the paper "Rheological Behaviour of Renewable Polyethylene (HDPE) Composites and Sponge Gourd (Luffa cylindrica) Residue" investigated effect of sponge gourd (cellulosic filler) in the concentration of 1040 wt.\% on rheological properties of high density polyethylene derived from sugarcane ethanol. This work shows that higher reinforcement of HDPE can be reached by an incorporation of cellulosic filler in the concentration above 20 wt. $\%$ but only with creations of agglomerates due to the low filler/matrix adhesion. The efficiency of fique fibres as a reinforcement low density polyethylene (LDPE) recycled from Tetra Pak was tested in the work of Hidalgo-Salazar et al. "Influence of Incorporation of Natural Fibers on the Physical, Mechanical, and Thermal Properties of Composites LDPE-Al Reinforced with Fique Fibers." J. S. Won et al. in the paper "Mechanical Properties and Biodegradability of the Kenaf/Soy Protein Isolate-PVA Biocomposites" modified mechanical properties and biodegradability of soy protein isolate/poly(vinyl alcohol) by an incorporation of kenaf nonwoven fabric. Effects of natural filler such as rice husk and pineapple leaves fibers on thermal, morphological, and mechanical properties of composites based on various polymer matrices such as polyethylene, polypropylene, polyvinylchloride, and poly(lactic acid) were reviewed in the works of R. Arjmandi et al. "Rice Husk Filled Polymer Composites" and M. Asim et al. "A Review on Pineapple Leaves Fibre and Its Composites." A fibre/polymer interfacial adhesion was highlighted as a main factor that influences final properties of natural fiber/polymer composites.

For practical uses of composites containing hygroscopic natural fibers it is very important to determine their mechanical properties under humid conditions to assess effect of moisture on their behavior. The issue of hygrothermal aging of kenaf fibers/polypropylene composites is addressed in the work of W. M. Haniffah et al. "Kenaf Fibre Reinforced Polypropylene Composites: Effect of Cyclic Immersion on Tensile Properties.” E. Muñoz and J. A. Garcia-Manrique in the paper "Water Absorption Behavior and Its Effect on the Mechanical Properties of Flax Fibre Reinforced Bioepoxy Composites" reported that composites based on biobased epoxy resin (SUPER SAP CLR Epoxy, Entropy Resins, USA) and 40 or 55 wt.\% of flax fiber woven fabric processed by resin transfer moulding process (RTM) in spite of the natural hygroscopicity of flax fibers can be an alternative to composites based on petroleum-based resins and synthetic fibers. F. J. Aranda-García et al. in the paper "Water Absorption and Thermomechanical Characterization of Extruded Starch/Poly(lactic acid)/Agave Bagasse Fiber Bioplastic Composites" improved mechanical properties of thermoplastic starch by incorporation of agave bagasse fibers and/or poly(lactic acid) (PLA). Moreover, water absorption of thermoplastic starch/agave bagasse fibers/PLA composites was in this formulation reduced. Effects of acetylation on alfa fibers and grafting of polypropylene (PP) with maleic anhydride on the final interfacial compatibility and hydrothermal stability of alfa fibers/PP composites were studied by $\mathrm{N}$. Hamour et al. in the paper "Effects of MAPP Compatibilization and Acetylation Treatment Followed by Hydrothermal Aging on Polypropylene-Alfa Fiber Composites."

The incorporation of natural fibers/filler requires a selection and a modification of common polymer processing methods and procedures to reach optimal physicomechanical properties of composites. M. D. Azaman et al. in the paper "Numerical Simulation Analysis of Unfilled and Filled Reinforced Polypropylene on Thin-Walled Parts Formed Using the Injection-Moulding Process" identified and compared residual stresses, volumetric shrinkages, and warpage in injected moulded thin-walled polypropylene specimens reinforced with 50 wt.\% wood filler and 10 wt.\% glass fibers. Z. Hutyrová et al. in the paper "Study of Surface Roughness of Machined Polymer Composite Material" investigated topography and surface properties of extruded wood fibers/HDPE composites and announced a presence of microcracks located on contacts between wood particles and polymer matrix.

This special issue provides up-to-date investigation of natural fibers as a source of renewable and biodegradable material available for use as reinforcements for polymers. Hopefully, this special issue will be beneficial to many scientists and move their research a small step forward.

Md. Saiful Islam Adriana Kovalcik Mahbub Hasan Vijay Kumar Thakur 

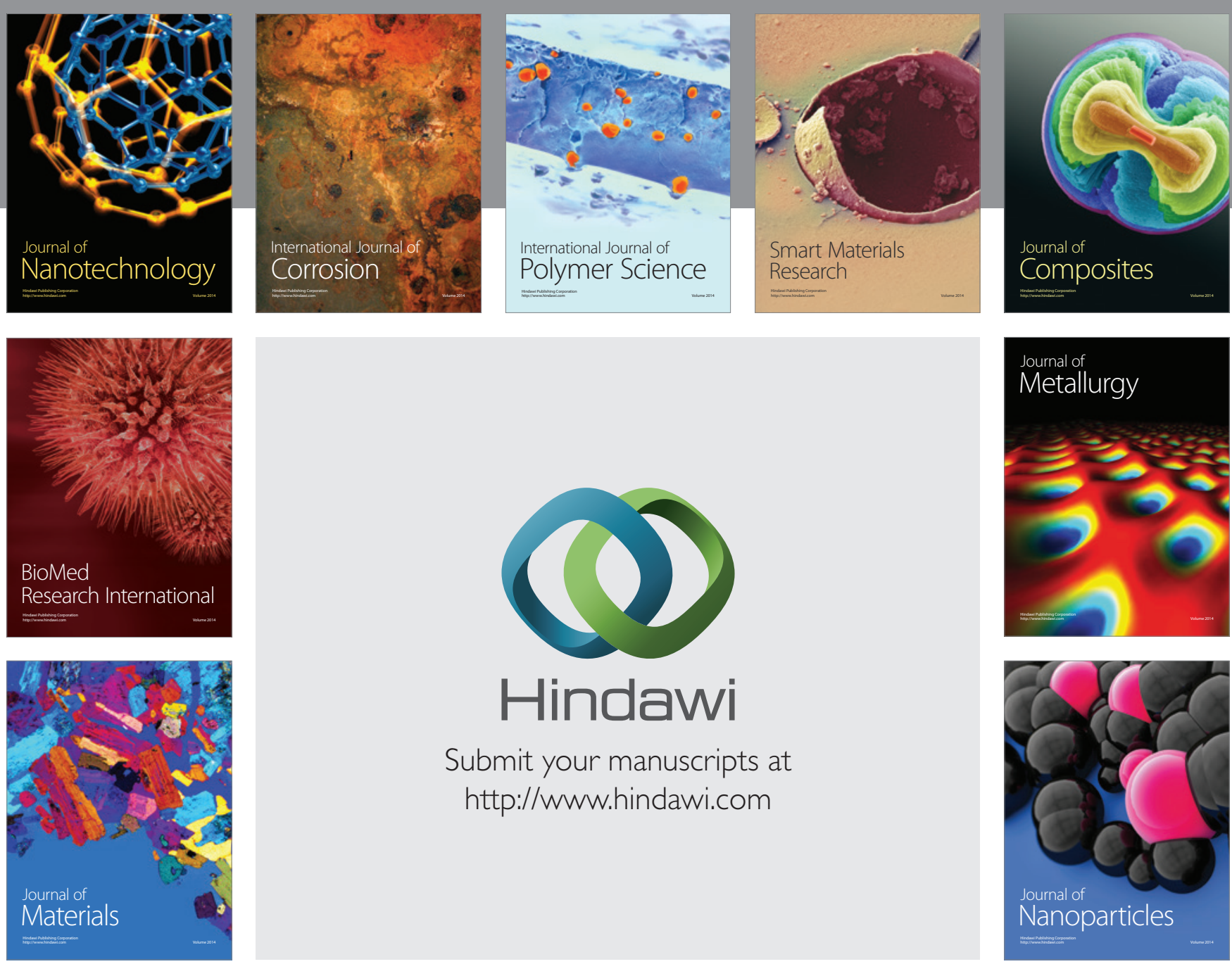

Submit your manuscripts at http://www.hindawi.com
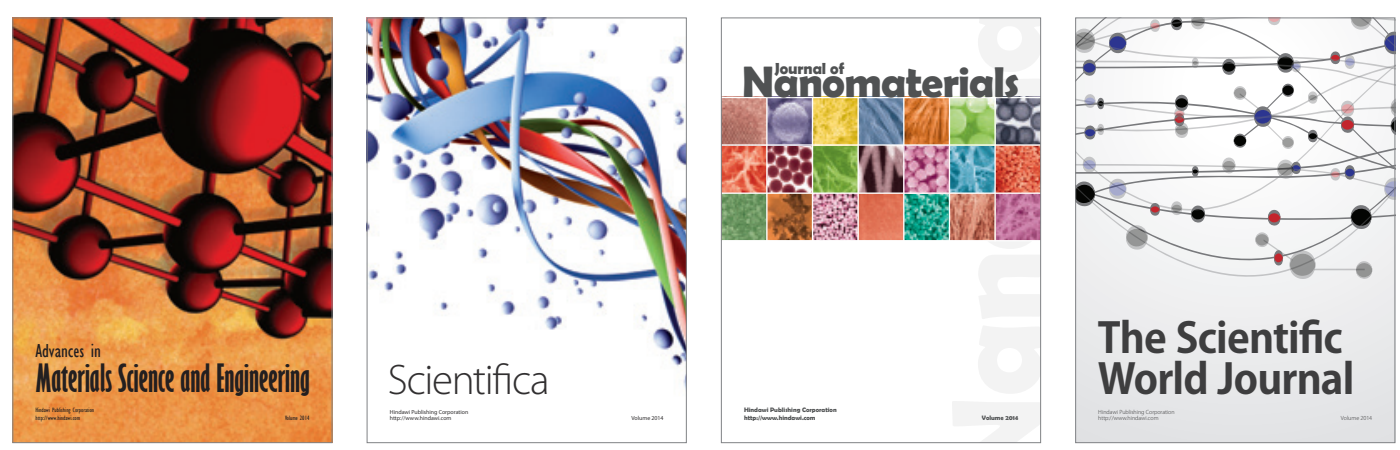

\section{The Scientific World Journal}
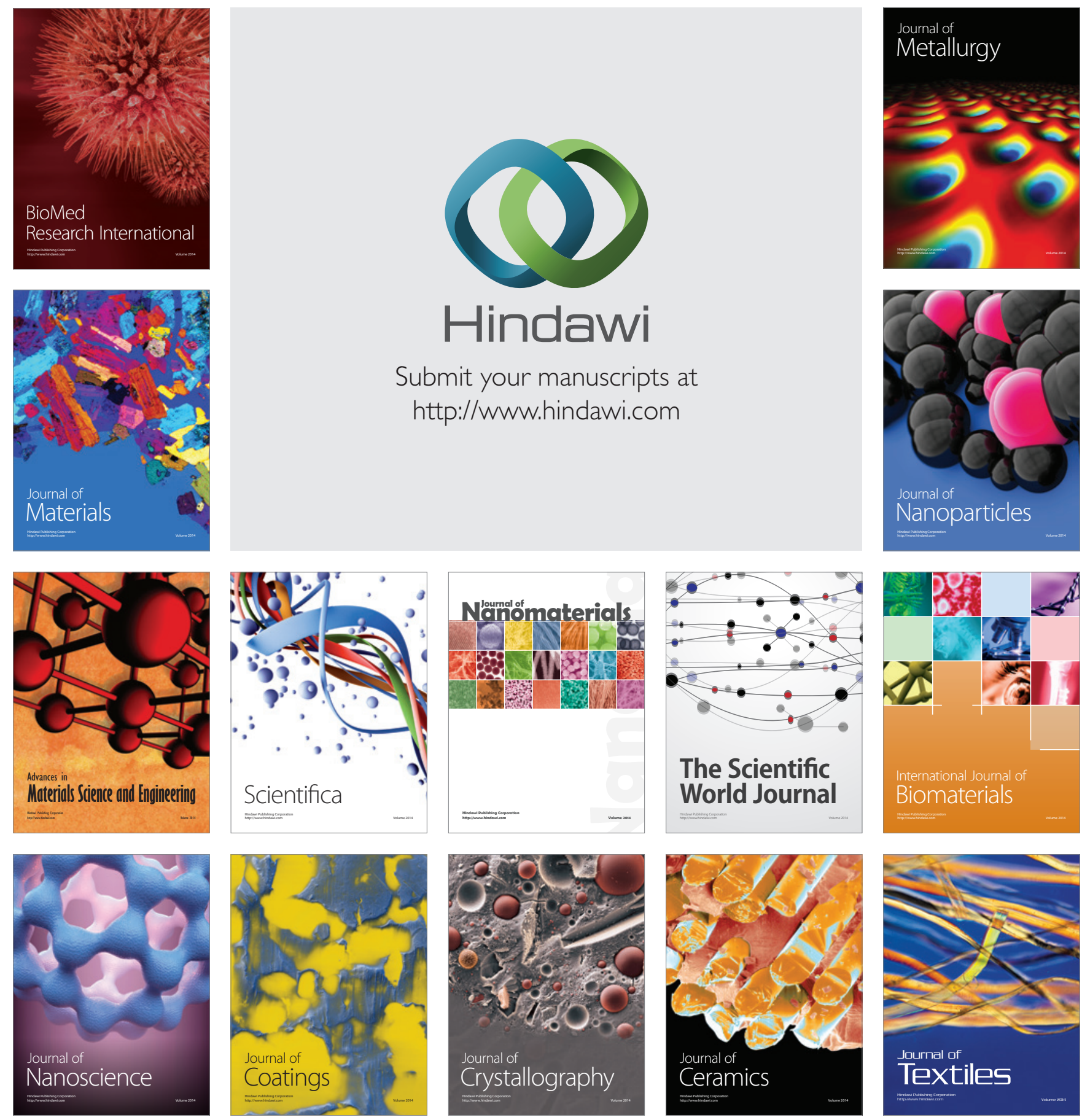